\title{
Button Batteries and Child Deaths: Market Failure of Unsafe Products
}

\author{
John Paull \\ University of Tasmania, Hobart, Tasmania, Australia.
}

How to cite this paper: John Paull. (2021) Button Batteries and Child Deaths: Market Failure of Unsafe Products. International Journal of Clinical and Experimental Medicine Research, 5(3), 297-303. DOI: 10.26855/ijcemr.2021.07.011

Received: April 26, 2021

Accepted: May 22, 2021

Published: June 15, 2021

*Corresponding author: John Paull, University of Tasmania, Hobart, Tasmania, Australia.

Email: j.paull@utas.edu.au

\begin{abstract}
Button batteries can be lethal if ingested and not promptly excreted or removed. These batteries are present in a multitude of household items including car remotes, IT devices, and many consumer items targeted at children. There are various technologies available for button batteries and they are produced in various sizes. Lithium button batteries with a diameter of $20 \mathrm{~mm}$ or more pose the greatest risk. Most at risk are children of 0-5 years. At this age, there is a propensity to put foreign objects in the mouth. These batteries once swallowed, rather than passing through the alimentary canal and being excreted, may lodge in the oesophagus where they will burn through tissue, sometimes trough to the trachea, sometimes through to the aorta. This will be fatal for the child if the problem is not promptly identified and the battery then promptly extracted. Death will follow within several weeks of ingestion, following episodes of ill health, if the problem is not recognised. The presenting symptoms of ill health by the child can be misdiagnosed as food poisoning, a virus, an infection, or some common malady. Three child deaths in Australia from ingested button batteries (all 20mm lithium) are reported in the present paper. In each case, after prior misdiagnoses, the ingested battery was detected by $\mathrm{X}$-ray, and, in each case, too late for successful intervention. Ingested button batteries can be detected by X-ray or ultrasound, but they may be indistinguishable from an ingested coin, which present less risk and are not actively corrosive. A new safety standard in Australia seeks to reduce the access of children to button batteries. The standard accepts the design status quo of button batteries, and seeks to avoid their misuse, in particular to stop them being ingested by young children. This is a safety-by-regulation approach. The alternative is a safety-by-design approach where the onus is on product designers to engineer safety into and danger out of the product. The twin problems of lithium button batteries are, firstly, their size where they are small enough to be easily swallowed by children but large enough to lodge in the oesophagus (where they are $\geq 20 \mathrm{~mm}$ in diameter), and secondly, their bio -reactivity with flesh, which is partly a matter of chemistry but also partly a matter of the surface areas of the electrodes (which are extensive surfaces rather than point electrodes).
\end{abstract}

\section{Keywords}

Coin cell batteries, button cell batteries, lithium batteries, product safety, product design, product recalls, consumer products, market failure, oesophagus, paediatric patient safety, electrode design, misdiagnosis, public health 


\section{Introduction}

Button batteries are small coin sized batteries that power car remotes and many other small and common consumer items, including toys and other powered items targeted at children. Such batteries can be fatal if ingested. Death by button battery can take from two to three weeks after ingestion. Young children (0-5 years) are most at risk. The batteries are shiny, attractive, and approximate the size of many sweets. Small children have a predilection for putting things in their mouth, and the size of these batteries make them easily swallowed (but not so easily excreted). Internal lodgement will prove fatal if not promptly removed.

Button batteries are compact single cell batteries, coin shaped, usually 5 to $25 \mathrm{~mm}$ in diameter, and 1 to $6 \mathrm{~mm}$ in height [1]. The button battery industry has been valued at US\$3.89 Billion [2]. Leading battery companies are involved, including Energiser, Maxwell, Mitsubishi, Panasonic, Seiko, Sony, Toshiba, and Varta [2, 3].

Such batteries - by size and chemistry — have been known to pose a serious risk to children if ingested, for more than a decade [4]. Common button batteries in the problematic category are coded as 'CR20', for example CR2025 and CR2032. The battery designation 'CR2032' is defined by international standard nomenclature and decodes as follows: $\mathrm{C}=$ electrochemical system, lithium; $\mathrm{R}=$ round; $20=20 \mathrm{~mm}$ diameter; $32=3.2 \mathrm{~mm}$ high [5].

The dangers to children of button batteries has been known "for several decades" [6]. A National Button Battery Task Force was set up in 2012 in USA [6]. More than 2,500 children ingest batteries per year in USA [7]. The Task Force report that: "most serious injuries are usually associated with $20 \mathrm{~mm}$ diameter batteries, about the size of a nickel, because they are likely to get lodged in a small child's esophagus. If a coin cell lithium battery becomes lodged in the esophagus it can cause tissue injury and necrosis within hours, leading to perforation or death of not removed urgently" [7].

Despite the parameters on danger being know (viz. $20 \mathrm{~mm}$ lithium button batteries) and safe-use advice [e.g. 8], the button battery problem persists, despite some concessions: "most manufacturers have improved warning labels, more secure packaging, and made BB compartments in products are more secure” [6, p. 149]. It is recorded that "Future BB [button battery] design changes could eliminate oesophageal tissue injury" [6, p. 149], but no such changes have been implemented, and serious injuries and deaths continue.

The ingestion of a button battery by a child may go unobserved, a missing discarded button battery is likely to go unnoticed, the child may be non-verbal or may otherwise not report the ingestion, there is a lag between ingestion and medical distress, and the medical symptoms of button battery ingestion are indistinguishable from many common childhood symptoms of non-fatal conditions. A child may initially be asymptomatic, or may exhibit non-specific symptoms "until catastrophic injuries develop over a period of hours or days" [9].

An ingested lithium button battery lodged in a child's oesophagus will corrode the adjacent flesh. "The electric charge produces sodium hydroxide, a caustic substance that is also the active ingredient in oven cleaner" [10]. This can result in burning through to the trachea (windpipe) or through to the aorta which will lead to massive haemorrhaging; such fistulas will be fatal [9]. The dangers have been identified as a public health issue, particularly because of "the rapid onset of full thickness burns and oesophageal perforation which may occur within as little as $2 \mathrm{~h}$ following the ingestion" [11, p. 1]. The particularity of the dangers are summed up: "Button batteries, unlike all other ingested foreign bodies, can cause catastrophic injuries (such as a tracheal- oesophageal fistula or a fatal oesophagi-aortic fistula) within hours of ingestion” [11, p. 1].

The bio-reaction is described as follows: "Impaction of button batteries results in the formation of local external current between the positive and negative poles of the battery ... to rapidly cause hydrolysis and hydroxide formation, leading to clinically significant burns and oesophageal perforation within as little as $2 \mathrm{~h}$ of ingestion” [11, p. 1].

Of 116 cases reported in Germany of a button battery lodged in the oesophagus of a child, severe complications were reported in 47 cases and deaths in 5 cases [12]. These authors describe button batteries as "a unique corrosive hazard" which, if impacted in the oesophagus should be removed as a matter of urgency. They warn that "no symptoms or only slight discomfort are developed initially” [12, p. 1354].

Of the various button battery technologies (alkaline, lithium, silver oxide, and zinc-air), it is the lithium batteries that pose the greatest danger. Ill health may quickly manifests following ingestion, but the correct diagnosis of the cause presents a challenge for practioners, and the symptoms can be attributed to various other maladies. Such misdiagnoses can have fatal consequences $[13,14]$. There may be a failure to recognise that a foreign body has been ingested, and, even with an X-ray, there may be a misdiagnosis as an ingested coin [11]. The present paper considers three child fatalities in Australia due to lithium button ingestion, the more general issue of ingestion where the outcome is not fatal, and makes some suggestions to avoid future fatalities. 
The dangers of button batteries are to children, most ingestions (68\%) are by children under 6 years old, most are unwitnessed ingestions (92\% of fatal ingestions), all fatalities were children under 4 years, and most (77\%) are confirmed by X-ray. For major injuries and fatal injuries most (92\%) were caused by $20 \mathrm{~mm}$ lithium batteries, and most of those (71\%) were CR2032 button batteries [4]. Many (54\%) of fatal ingestions are initially misdiagnosed, "presentations generally suggested other, more common diagnoses" with "CR2032, the cell most frequently implicated in major and fatal outcomes" [4, p. 1174].

\section{Material and methods}

There have been two inquests in Australia into child deaths from button batteries (also called coin batteries and coin cells) and the findings of these Inquests $[13,14]$ were available for the present paper. The Australian Competition \& Consumer Commission (ACCC) has prepared an Issues Paper on Button Battery Safety [15] and a report to the Minister for Housing of the Australian Government [16] and a specific new safety standard [17, 18] has been subsequently implemented in the light of the report; these documents were available for the present paper. Product Safety Australia oversees and aggregates product recalls and button battery device recalls [19] were reviewed for the present paper. The Australian media has played a key role in shining a spotlight on the tragedies of child deaths from ingested button batteries, and various media accounts were available for the present paper.

\section{Results}

Three children have died in Australia from button battery ingestion: four-year-old Summer in 2013; fourteen-month-old Isabella in 2015; and three-year-old Brittney in 2020. All three deaths were caused by 20mm diameter lithium batteries [16]. Such batteries are common for car remotes and many other small appliances. In each case, the initial medical diagnoses were incorrect, the battery ingestion by the child was not witnessed and the source of the battery was unknown (Table 1).

The button battery problem is a known problem: "Increasingly frequent, devastating complications from button battery ingestions are associated with 20-mm lithium cells. Removal from the esophagus must be accomplished within 2 hours. Misdiagnoses and delays have caused perforations, strictures, fistulas, vocal cord paralysis, exsanguination, and 13 reported deaths" [4, p. 149].

All three girls presented, on multiple occasions, along with their parents, to general practitioners and hospitals. They were each misdiagnosed on multiple occasions, until finally an x-ray revealed the ingested object, at which time, in each case, the condition of the patient was terminal and death quickly followed $[10,13,14,16]$.

Table 1. Child button battery deaths in Australia

\begin{tabular}{|c|c|c|c|c|c|c|c|c|c|}
\hline Child & Age & $\begin{array}{l}\text { Date of } \\
\text { death }\end{array}$ & $\begin{array}{l}\text { Battery } \\
\text { type }\end{array}$ & $\begin{array}{l}\text { Source } \\
\text { of } \\
\text { battery }\end{array}$ & $\begin{array}{l}\text { Ingestion } \\
\text { witnessed } \\
?\end{array}$ & $\begin{array}{l}\text { \# of medical } \\
\text { presentations }\end{array}$ & $\begin{array}{l}\text { Early } \\
\text { diagnosis }\end{array}$ & X-ray? & $\begin{array}{l}\text { Ingestion } \\
\text { to death }\end{array}$ \\
\hline Summer & 4 years & $\begin{array}{l}30 \text { June } \\
2013\end{array}$ & $\begin{array}{l}20 \mathrm{~mm} \\
\text { Lithium }\end{array}$ & Unknown & No & $\geq 4$ & $\begin{array}{l}\text { gut } \\
\text { infection } \\
\text { (giardia) }\end{array}$ & $\begin{array}{l}2 \mathrm{~h} 15 \mathrm{~m} \\
\text { before she } \\
\text { died }\end{array}$ & $\begin{array}{l}\text { c. } 2-3 \\
\text { weeks }\end{array}$ \\
\hline Isabella & 14 months & $\begin{array}{l}4 \\
\text { February } \\
2015\end{array}$ & $\begin{array}{l}20 \mathrm{~mm} \\
\text { Lithium } \\
\text { (CR2025 } \\
\text { Energiser) }\end{array}$ & Unknown & No & $\geq 4$ & $\begin{array}{l}\text { urinary } \\
\text { tract } \\
\text { infection }\end{array}$ & $\begin{array}{l}<3 \text { hours } \\
\text { before she } \\
\text { died }\end{array}$ & $\begin{array}{l}19 \text { days } \\
\text { of ill } \\
\text { health }\end{array}$ \\
\hline Brittney & 3 years & $\begin{array}{l}28 \text { July } \\
2020\end{array}$ & $\begin{array}{l}20 \mathrm{~mm} \\
\text { Lithium }\end{array}$ & Unknown & No & $\geq 4$ & $\begin{array}{l}\text { food } \\
\text { poisoning }\end{array}$ & $\begin{array}{l}8 \text { days } \\
\text { before she } \\
\text { died }\end{array}$ & 3 weeks \\
\hline
\end{tabular}

\subsection{Four-year-old Summer (2009-2013)}

The Inquest into the death of Summer found that: "When a lithium button battery is ingested, saliva triggers the battery to generate an electrical current, resulting in chemical burns caused by the electrolysis of tissue fluids and hydroxide produced" and that "the danger exists even for so called 'flat' button batteries, which will not operate devices" [13, p. 6].

For Summer, the coroner identified inadequate performances of the initial general practitioner (on 17 June and 21 
June, 2013) and subsequently of the initial doctor at a private hospital (30 June) [13]. The coroner reported that: "The first anyone knew that Summer had swallowed the battery was around 11:30am on 30 June 2013 when it was discovered by chance in an X-ray. Summer was dead by 1:45pm" [13, p. 7]. On that day, Summer had been at the Noosa Private Hospital since 1:45am. The coroner observed that: "with the benefit of hindsight ... the black stools was Melaena (blood in the stools) caused by slow bleeding from the battery ulceration site" [13, p. 8]. Summer had been vomiting blood. Finally, "A routine post intubation chest x-ray was taken soon after the intubation and revealed a 2cm diameter battery sitting in Summer’s mid oesophagus” [13, p. 40].

A medical opinion of Summer's cause of death was stated as: "Haemorrhage, due to, or as a consequence of ... Aorto-oesophageal Fistula, due to, or as a consequence of ... Oesophageal Foreign Body (Battery)” [13, p. 42]. To avoid a repeat of Summer's tragedy, the coroner made 13 recommendations addressing the actors in the chain of events, including battery manufacturers, product manufacturers, federal and state governments, the medical profession, the ambulance service, the hospital, and the general practitioner.

The coroner stated: "Summer died because the button battery she ingested lodged in oesophagus, which caused haemorrhaging, and led to an aorta-oesophageal fistula” [13, p. 6].

\subsection{Fourteen-month-old Isabella (2013-2015)}

The death of 14 month old Isabella echoed the experience of Summer. Isabella presented at the Sunshine Hospital Emergency Department, initially on 16 January 2015, and on three further occasions. On the final visit she arrived at 5:32am. An X-ray revealed a foreign body in her oesophagus. It was a $20 \mathrm{~mm}$ lithium button battery (an “Energizer CR2025 3 Volt lithium battery”) [14, p. 5]. Isabella was declared dead at 8:40am [14].

The cause of death was stated as: "Gastrointestinal haemorrhage ... Aorto-oesophageal fistula ... Foreign body in the oesophagus (button battery" [14, p. 5]

Isabella was taken to the Sunshine Hospital Emergency Department on four occasions. On the first occasion, 16 January 2015, Isabella was projectile vomiting, was taken to the hospital, was managed with ondansetron and paracetamol, and was discharged. On 19 January, she was taken to the hospital again with a fever. She was diagnosed with a urinary tract infection (UTI), prescribed antibiotics, and discharged. Mrs Rees stated that "I changed her nappy while waiting at the hospital and there was diarrhoea and ... There was also black poo which was really unusual. It was extra smelly, a different smell" which she states she "showed to the nurse and to every doctor we saw there" [14, p. 10]. Isabella attended again on 21 January for a planned review and was discharged with instructions to complete the course of antibiotics. The fourth and final visit to the hospital was on 4 February (5:32 am) reporting blood on her bedding and vomiting blood at the hospital. Finally, an X-ray revealed a foreign body in the oesophagus. Isabella had a cardiac arrest at 7:00am and was resuscitated and received a blood transfusion. She had another cardiac arrest at 7:46pm. Resuscitation efforts were unsuccessful. She was declared deceased at 8:40am [14].

At the Inquest "Bella's family raised concern about the medical care and treatment Isabella received on her presentations to Sunshine Hospital. These focussed on their concerns raised at a very early stage that Isabella may have swallowed something which were not recorded in the hospital medical notes or referenced in statements made by hospital staff for the coronial investigation" [14, p. 5]. The coroner states "I found the evidence of $\mathrm{Mr}$ and Mrs Rees to be credible and compelling. I note Mrs Rees ... referenced her frustrations that at times she felt the family were not listened to or believed" [14, p. 17].

\subsection{Three-year-old Brittney (2017-2020)}

The death of three year old Brittney, followed a similar pattern of events to Summer and Isabella; she died on 28 July 2020. Three weeks prior, she had ingested a $20 \mathrm{~mm}$ lithium button battery which lodged in her oesophagus. After misdiagnoses by a general practitioner and a hospital, an X-ray revealed a button battery. Despite the discovery and several surgeries, Brittney died eight days after the X-ray [16].

The initial diagnosis was "suspected food poisoning" [10]. Days later her mother took her to the Robina Hospital emergency department battery and also a general practitioner (GP). A week later, an X-ray revealed a button battery lodged in her oesophagus. Surgeons operated to remove the battery and repair the damage but the battery had had burned through her oesophagus to her aorta and caused major bleeding [10].

Dr Hanna Burns, paediatric ear, nose and throat (ENT) surgeon who worked on Summer observed that: "Whenever we hear a child has swallowed a button battery and there's bleeding associated with that, we know almost universally that's going to be a fatal injury" [10]. 


\subsection{Button battery device recalls}

There have been 154 reported product recalls for button battery devices. These recalled devices are almost all domestic products and 44 are categorised as "Babies and kids". It is the second largest category, after 81 recalls categorised as "Electronics and technology" [19]. These dangerous product recalls include items specifically targeted at children and marketed by major retailers and organisations to children including by: Kmart, Target, Woolworths, Big W, Smiggle, Cotton On, Village Roadshow, Commonwealth Bank, and the Australian Football League (AFL) [19].

The button battery recalls date from 1998 through to the present. The most recent (9 February, 2021) is "Kaiser Kids Slap Band Watches with various character faces. Various colours". The defects, hazards and the consumer remedy offered for these products are typical:

What are the defects? The products do not comply with the 'Consumer Goods (Products Containing Button/Coin Batteries) Safety Standard 2020. If the watch face is removed from the slap band, the battery compartment of the watch is not adequately secured and the button battery in the product is easily accessible [19]. What are the hazards? If young children gain access to the button batteries and ingest them, they may suffer internal burn injuries, which can result in serious illness and even death. In addition, the batteries may pose a choking hazard to young children [19].

What should consumers do? Consumers should immediately stop using the products and return them to the nearest Kaisercraft store to receive a full refund [19].

Items in the154 recalls were offered variously in retail stores and online, and awareness of the danger and of the prevailing safety regulations appear to have failed to be embraced by the corporate buyers. These corporations and individuals, whose job it is to know the hazards and the standards and apply due diligence, are failing children, as evidenced by the continuing recalls of dangerous button battery devices.

\subsection{Regulation}

Driven by tragedies of child injuries and deaths, the Australian Competition and Consumer Commission (ACCC) presented recommendations to the Australian Government on the basis that "there is a market failure with regard to the safety of button batteries and consumer goods that contain these batteries. Mandatory regulation is necessary to prevent deaths and severe injuries to children" [16, p. 3].

Just a month after the ACCC recommendations, in December 2020, Australia instated new regulations: Consumer Goods (Products Containing Button/Coin Batteries) Safety Standard 2020 (Cth) (the Regulations). The approach of these Regulations is to offer denial of access (Denial-of-access) to children (the at-risk population) to button batteries, rather than to adopt a safe by design (safe-by-design) approach [23].

There are four requirements in the Standard: (i) "Button/coin batteries must not release during reasonably foreseeable use or misuse conditions"; (ii) "Compartment holding button/coin batteries must be resistant to being opened by young children"; (iii) "Fasteners for doors or covers to compartments holding button/coin batteries must be captive", i.e. the screws or fasteners used to secure the compartment "are captive and remain with the door or cover"; and (iv) "Secureness of consumer goods with non-replaceable button/coin battery accessible by consumers must be tested" [17, pp. 6-7].

These button battery Standard is described as a "world first" [10, p. 30]. There is the view that Australia can "have a leading role in the development of button battery requirements globally" [16, p. 4]. The explanatory statement associated with the standard states that the objective is "to reduce the risk of fatality and injury ... button/coin batteries can cause severe injury and even death if swallowed, particularly for young children aged 0-5 years” [18, p. 1].

Of the four technologies of button batteries (lithium, alkaline, silver oxide and zinc air), lithium batteries are singled out as posing the highest risk: "their typically larger diameter means they are more likely to become stuck in a child's oesophagus if ingested and their higher voltage means they can cause tissue damage more quickly" [18, p. 1].

The cost of button battery related "fatalities, injuries and exposures" to the Australian economy is estimated at A $\$ 4.7$ million per annum (US\$3.7m; $€ 3.1 \mathrm{~m}$ ). The "children gained access to button/coin batteries directly from the product in almost two thirds of cases” [18, p. 1]. One estimate is that there are approximately 900 emergency presentations per annum for suspected button battery ingestion [16]. Some children sustain lifelong injuries.

Extrapolating from the Australian experience of circa 900 suspected button battery ingestions (for a population of 25.4 million), suggests that the global number of such ingestions could be in the order to 280,000 per annum (for a 
world population of 7.7 billion).

\section{Concluding remarks}

Children are at risk from the ingestion of button batteries. However, "Button batteries, per se, are not the problem. The outcome of ingestion is determined by the battery chemistry and the battery diameter" [4]. Of the handful of button battery technologies and the multiplicity of sizes, it is lithium button batteries of $20 \mathrm{~mm}$ diameter that are the most problematic. At $20 \mathrm{~mm}$, they are prone to lodge in a child's oesophagus (smaller batteries do not present the same risk), and lithium batteries are particularly corrosive once lodged, with lifelong damage inflicted in some cases, and with fatal outcomes in some instances.

The problems of $20 \mathrm{~mm}$ lithium button batteries were known and described more than a decade ago. The rapidity of harm onset was known: "severe injury can occur in just 2 hours" [4, p. 1176]. The mechanisms of harm were known: "The negative battery pole, identified as the narrowest side on lateral X-ray, causes the most severe, necrotic injury. The negative battery pole is the side opposite the '+' and without the imprint ... 20-mm lithium coin cell is most frequently involved in esophageal injuries; smaller cells lodge less frequently ... tracheoesophageal fistulas became symptomatic within 9 days after battery removal, but the most frequent fatal complication—fistulization into an artery-manifested as late as 18 days after removal” [4, pp. 1175-6].

While Australia's new safety standard for button batteries $[17,18]$ is a welcome move for child safety, it is just a step on a pathway to safety. Button batteries, particularly lithium button batteries are present in a multitude of household items and they can be lethal for young children. Further research is called for to make these batteries safe-by-design rather than rely on the more problematic option of denial-of-access approach of the Standard.

Safety by regulation has addressed the safety issues by a denial-of-access approach. The batteries are sold in 'child-proof' packaging and the batteries are secured in products so as to require some tool for extraction and battery replacement. However, for the child deaths reported in the present paper, there is no evidence or even any suggestion that the ingested batteries were unpacked or extracted by the child. The source of the three fatal batteries was not identified.

The prevailing design of button batteries is unsafe by design, somewhat reminiscent of the automotive industry decades ago [24]. The presenting surfaces of button batteries are mostly terminal, with one face the positive, the other face the negative, with these faces separated by a gasket (e.g. Duracell CR2032). This design maximises the opportunity (surface area) for bio-reaction and tissue damage if ingested. One safe-by-design consideration is to reduce the diameter of button batteries so that they are less likely to lodge in a child's oesophagus, and are more likely to pass through in faeces. Another safe-by-design approach would be to adopt recessed pin-point size terminals so that the surface area for bio-reaction is minimised (batteries with such terminals, e.g. Canon NB-11L, are typical in digital cameras).

Button battery injuries and fatalities call for trans-disciplinary safe-by-design research, including consideration of the physical lodgement characteristics of such batteries, bio-reactivity mitigation, and the diminution of the psychological attractiveness of batteries (to children). Sheeting the locus of liability for product safety back to button battery manufacturers is likely to accelerate a safe-by-design reconfiguration (or perhaps elimination) of button batteries.

There is the opportunity to ban $20 \mathrm{~mm}$ lithium button batteries. This could be done by legislation. It could be done by litigation. Successful individual or class actions for negligence, injury, and unlawful death, on behalf of injured parties, if the penalties were steep enough, would deter battery and product manufacturers and retailers from persisting with such unsafe products. The withdrawal of a social licence for such unsafe products may offer a path to termination; this may occur through consumer boycott or shaming via social media. There can be a point where shareholders are sufficiently 'spooked' by litigation, social media, and/or withdrawal of social licence, that the unsafe products are extinguished by shareholder disquiet.

The opportunity for battery and product manufacturers is to use smaller diameter button batteries, ones without a propensity for lodging in a child's oesophagus if ingested. It would also be an addedplus if the technology of such batteries does not exhibit the bio-corrosive properties of lithium button batteries. The button battery problem (of child injuries and deaths) reflects poorly on the button battery industry. The problem is wholly of the making of the button battery industry. The problem is of the few, not of the many button batteries, but, if the safety issues of $20 \mathrm{~mm}$ lithium button batteries are not resolved, then the reputation of the whole industry is tarnished. If the prevailing market failure of button batteries persists, then the 'dead hand' of legislation, regulation, litigation, retailer push-back, and/or public shaming may resolve the problem of the few by punishing the many, to the detriment of the button battery industry as well as of the consumer. 


\section{References}

[1] Wiseguy Research Consultants, Global Button Batteries Market Size study, Type (Alkaline Batteries, Silver Oxide Battery and Others), Application (Digital Products, Toy, Medical Instruments and Others) and Regional Forecasts 2019-2026. 2021, Pune, India: Wiseguy Research Consultants.

[2] Credence Research, Coin Cell Batteries Market by Product (LR, SR, CR, ZnAIR), by Application (OEM, Demand, Retail, Others) -Growth, Furure Prospects and Competetive Analysis 2019-2027. 2019, Pune, India: Credence Research.

[3] Industry Growth Insights, Global Button Batteries (Button Cell) Market by Type (Alkali, Organic), By Application (Watches, Medical Devices (artificial cardiac pacemakers,implantable cardiac defibrillators,hearing aids), Automobile, Others) And By Region (North America, Latin America, Europe, Asia Pacific and Middle East \& Africa), Forecast To 2028. 2020, Punen, India: Industry Growth Insights.

[4] Litovitz, T., et al. (2010). Emerging battery-ingestion hazard: clinical implications. Pediatrics, 2010, 125(6): 1168-1177.

[5] IEC, International IEC Standard 60086-2: Primary batteries-Part 2: Physical and electrical specifications. 2001, Geneva: International Electrotechnical Commission (IEC).

[6] Jatana, K. R., et al. (2018). Button Battery Safety: Industry and Academic Partnerships to Drive Change. Otolaryngologic Clinics of North America, 2018, 52(1): 149-161.

[7] Button Battery Task Force, The Hazards of Button Batteries. 2019, Itasca, IL: American Academy of Pediatrics.

[8] GOSH, Button batteries_ - using them safely. 2018, London: Great Ormond Street Hospital for Children NHS Foundation Trust (GOSH).

[9] Jatana, K. R., et al. (2013). Pediatric button battery injuries: 2013 task force update. International Journal of Pediatric Otorhinolaryngology, 2013, 77(9): 1392-9.

[10] Clark, M., A. Gaffney, and S. Cheney. (2021). Landmines in the loungeroom. ABC News, 2021. 15 February.

[11] Semple, T., et al. (2018). Button battery ingestion in children-a potentially catastrophic event of which all radiologists must be aware. British Journal of Radiology, 2018, 91(20160781): 1-4.

[12] Gerner, P., et al. (2019). Gesundheitsschäden nach Ingestion von Knopfzellbatterien im Kindesalter [tr: Health damages after ingestion of button batteries in childhood]. Bundesgesundheitsblatt Gesundheitsforschung Gesundheitsschutz, 2019. 62(11): $1354-1361$.

[13] Hutton, J. (2015). Inquest into the death of Summer Alice STEER. 2015, 3 November. Sunshine Coast: Coroners Court, Queensland Courts.

[14] English, C. (2019). Inquest into the death of: Isabella Estelle Rees. 2019, 4 April. Melbourne: Coroners Court of Victoria.

[15] ACCC. (2019). Button Battery Safety Issues Paper. 2019, Canberra: Australian Competition and Consumer Commission (ACCC).

[16] ACCC. (2020). Button Battery Safety: Final Recommendation to the Minister. 2020, Office of Best Practice Regulation Reference 25774. November. Canberra: Australian Competition and Consumer Commission (ACCC).

[17] Sukkar, M. (2020). Consumer Goods (Products Containing Button/Coin Batteries) Safety Standard 2020 (Cth). 2020,18 December. F2020L01656. Canberra: Commonwealth of Australia.

[18] Sukkar, M. (2020). Explanatory Statement: Consumer Goods (Products Containing Button/Coin Batteries) Safety Standard 2020 (Cth). 2020, 18 December. F2020L01656. Canberra: Commonwealth of Australia.

[19] ACCC. (2021). Recalls: Button Battery. 2021, Product Safety Australia. Canberra: Australian Competition and Consumer Commission (ACCC) <productsafety.gov.au> 30 March.

[20] van Vonderen, J. (2015). Summer Steer: Queensland coroner calls for safer batteries after inquest into death of four-year-old. ABC News, 2015. 3 November.

[21] Cunningham, M. (2019). Our beautiful Bella could have been saved: Coroner calls for statewide guidelines after baby battery death. The Age, 2019. 4 April.

[22] Zappavigna, A. (2020). Three-year-old girl dies after swallowing common household item. 9News, 2020. 24 October.

[23] eSafety Commissioner, Safety by Design Overview. 2019, Sydney, NSW: Offfice of the eSafety Commissioner.

[24] Nader, R. (1985). Unsafe at any Speed: The designed-in dangers of the American automobile. 1985, New York: Grossman Publishers. 